\title{
Development of a Generic Model of a Ruthenium Reactor
}

\author{
Norbertin Nkoghe Eyeghe ${ }^{\mathrm{a}}$, Carl Sandrock ${ }^{\mathrm{b}}$ and Carel Van Dam ${ }^{\mathrm{b}}$ \\ ${ }^{a}$ Department of Chemical Engineering; University of Pretoria; Pretoria, South Africa \\ ${ }^{\mathrm{b}}$ Department of Chemical Engineering; University of Pretoria; Pretoria, South Africa \\ carl.sandrock@up.ac.za
}

\begin{abstract}
A mathematical first-principle model (FPM) of a ruthenium reactor was developed, implemented and successfully validated against a set of measurements of the real reactor of a precious metal refinery (PMR). The model describes the dynamic behavior of a process involving two exothermic reactions, occurring simultaneously in a semi-batch reactor equipped with a jacket. The reactions describe the dissolution of solid ruthenium $(\mathrm{Ru})$ to produce liquid ruthenium trichloride $\left(\mathrm{RuCl}_{3}\right)$, which is then evaporated into ruthenium tetroxide gas $\left(\mathrm{RuO}_{4}\right)$. This paper presents a lumped model of the process whose main objective was to achieve satisfactory tracking of temperature and pressure data sets of the real reactor. The model was written as an explicit system of ordinary differential equations (ODEs), and has demonstrated satisfactory predictions of temperature and pressure dynamics. However, more work aiming at achieving better validation of the model is still in progress. This involves using nonlinear optimization techniques to find optimum parameter estimates of reaction kinetics constants, together with some heat and mass transfer coefficients, only obtained by trial-and-error at this point.
\end{abstract}

Keywords: FPM, ODE, Estimation, Semi-batch Reactors, Model Validation.

\section{Introduction}

Mathematical models can be built to describe various dynamic behaviors taking place in systems of continuous, batch or semi-batch processes. A ruthenium semi-batch reactor is such a system for which a mathematical model can be developed. Ruthenium is a precious metal, an element of the platinum group metals (PGMs). It is regarded as a specialty product and often processed in batch or semi-batch reactors, operating sequentially through the phases of heating, reaction, cooling and filtering. Modeling the ruthenium reactor involves capturing such reaction dynamics that are descriptive of the operation of a semi-batch reactor.

Two types of models are commonly developed and used. They are empirical models (EM) and first-principles models (FPM). The former are generated by fitting a polynomial algorithm to a set of data, using model identification techniques provided by commercial software packages. The latter are developed by capturing dynamic behaviors describing their systems. This is done by applying the principles of conservation laws of mass and energy balances in the mathematical formulations of either ODEs or DAEs. Those models are built and solved in numerical platforms, their formulation, development and numerical integration can become more difficult with large and complex systems (Pantelides and Renfro (2013)).

Although first-principle modeling of batch and semi-batch reactors have been well addressed in the scientific literature, there is still little work that has been published on PGMs related processes. However, all dynamic FPMs of batch and semi-batch reactors are based on the same mathematical principles regardless of the process recipe. Nyström (2007) has reported that processes are mod- 
eled using DAEs or ODEs, consisting of differential equations that describe the dynamic behavior of the system, as mass and energy balances, and algebraic equations that ensure physical and thermodynamic relations. The same mathematical principles have been reported on by Prokopová and Prokop (2009). FPMs have been developed and validated to predict temperature behaviour of an industrial, semi-batch, emulsion polymerization reactor (Hvala and Kukanja (2013), Hvala et al. (2011)).

\section{System Description}

The system is a jacketed semi-batch reactor (see Figure 1), in which two exothermic reactions take place simultaneously, according to the following chemical equations of reactions.

$$
\begin{aligned}
\mathrm{Ru}(\mathrm{s})+\mathrm{Cl}_{2}(\mathrm{~g}) & \rightarrow 2 \mathrm{RuCl}_{3}(\mathrm{l}) \\
2 \mathrm{H}_{2} \mathrm{O}(l)+2 \mathrm{RuCl}_{3}(l)+2 \mathrm{NaClO}_{3}(l) & \rightarrow 4 \mathrm{HCl}(\mathrm{l})+2 \mathrm{RuO}_{4}(\mathrm{~g})+\mathrm{Cl}(\mathrm{g})+2 \mathrm{NaCl}(\mathrm{l})
\end{aligned}
$$

Steam and cooling water are the hot and cold utilities used to regulate the temperature conditions of the reactor during the process. The first reaction (Eq.1), describes the dissolution of solid ruthenium $(\mathrm{Ru})$ in the presence of chlorine $\left(\mathrm{Cl}_{2(\mathrm{~g})}\right)$ to produce ruthenium tri-chloride $\left(\mathrm{RuCl}_{3(\mathrm{l})}\right)$. The second reaction (Eq.2) describes the evaporation of $\mathrm{RuCl}_{3(1)}$ in the presence of sodium chlorate $\left(\mathrm{NaClO}_{3(\mathrm{l})}\right)$, used as the oxidizing agent, to produce ruthenium tetroxide $\left(\mathrm{RuO}_{4(\mathrm{~g})}\right)$ as the main product, sodium chloride $\left(\mathrm{NaCl}_{(\mathrm{l})}\right)$ and Hydrochloric acid $\left(\mathrm{HCl}_{(\mathrm{I})}\right)$ as by-products.

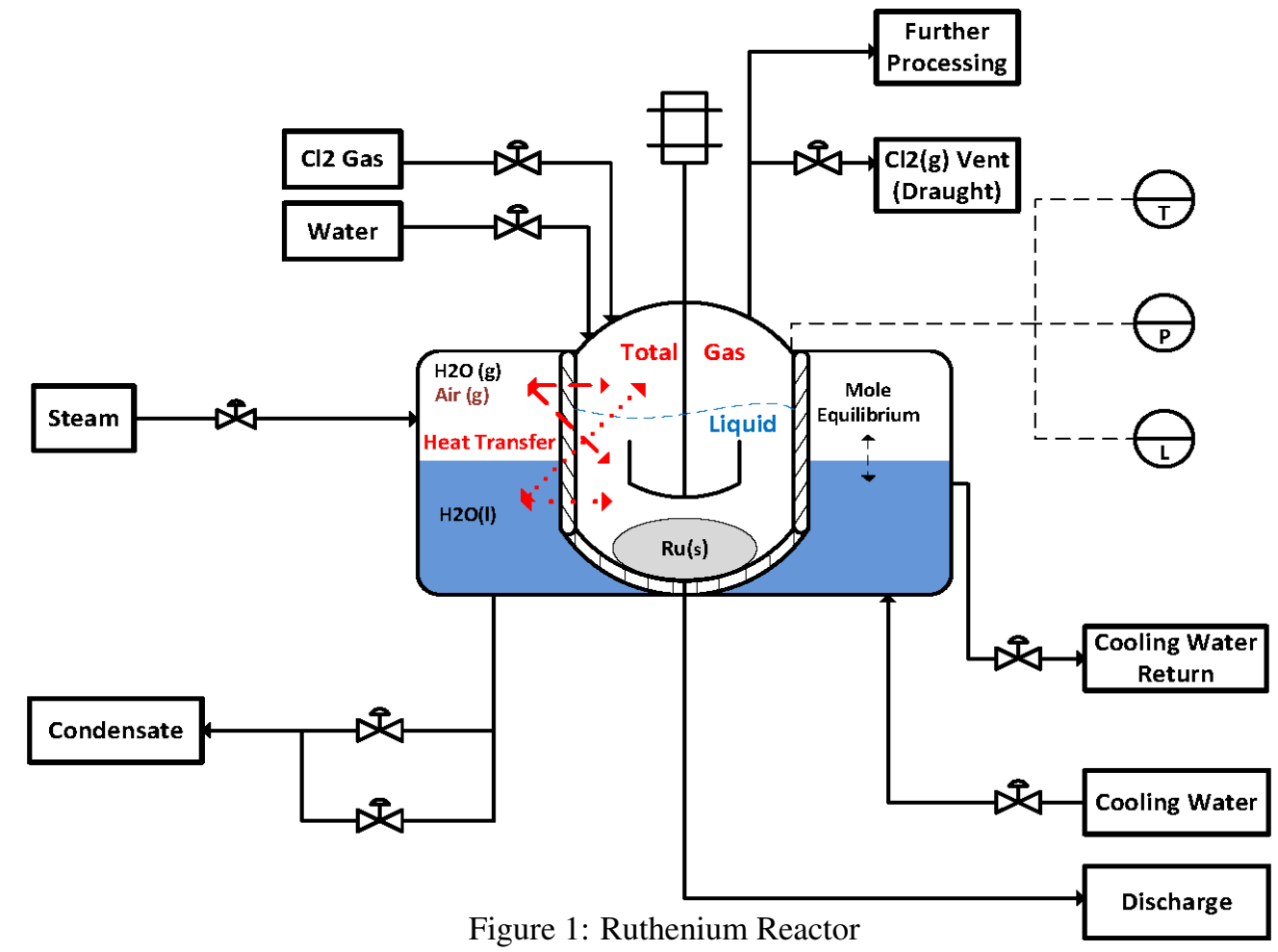

The process takes place in five phases. The first phase involves loading the reactor with $\mathrm{H}_{2} \mathrm{O}_{(\mathrm{l})}$, $\mathrm{Ru}_{(\mathrm{s})}$ and catalyst $\mathrm{NaClO}_{3(1)}$. The second phase involves heating the reactor up to a temperature of about $40{ }^{\circ} \mathrm{C}$ by introducing steam into the jacket. The third phase is the chlorination, where $\mathrm{Cl}_{2(\mathrm{~g})}$ is added into the reactor and dissolves into water to react with $\mathrm{Ru}_{(\mathrm{s})} \cdot \mathrm{Cl}_{2(\mathrm{~g})}$ is also used to maintain the reaction pressure condition to the required operational level of $\pm 400 \mathrm{kPa}$. At this point the reaction phase starts, steam is cut off and the exothermic reactions proceeds. The last phase involves cooling the reactor by pumping cooling water into the jacket at the end of the batch. The phases of heating, cooling and chlorination take place simultaneously with the reaction phase. Utilities are pumped alternately into the jacket to regulate the reaction temperature such that there be no temperature runaways, leading to potentially dangerous situations. 


\section{Model Development}

The mathematical model of the reactor was developed with respect to the chemical reactions of Eq.1 and Eq.2. Those reactions were modeled primarily to lump the reaction heat to be handled and the transport dynamics between the jacket and reactor compartments. In the system, temperature and pressure are the most important variables for the initial control situation. The model was developed and implemented in the "Matlab" computational environment.

\subsection{Explicit ODE Model}

The equations were written as an explicit system of ODEs, with a total of 115 equations describing the system, of which, 18 are differential equations and 97 algebraic equations. They were written for the solid, liquid, and gas phases. $\mathrm{Ru}$ is the solid specie. $\mathrm{H}_{2} \mathrm{O}, \mathrm{Cl}_{2}, \mathrm{RuCl}_{3}, \mathrm{HCl}, \mathrm{NaClO}_{3}$ and $\mathrm{NaCl}$ are in the liquid phase, and $\mathrm{H}_{2} \mathrm{O}, \mathrm{Cl}_{2}, \mathrm{RuO}_{4}$ are in the gas phase. Matlab solver "Ode15s" was used for numerical integration. The model was subject to the following assumptions:

- The reactor solution is perfectly mixed.

- There is negligible heat loss to the surroundings.

- The solutions are ideal (i.e molar concentrations considered instead of activity coefficients).

- Ionic species do not contribute to volume but do contribute to density.

- There is a mixed phase (liquid and gas) into the jacket compartment at all times.

- The dynamics of the reactor wall are neglected, to enhance direct heat transfer.

The model parameters of heat and mass transfers coefficients, as well as reaction kinetic constants were estimated by trial-and-error, as no experimental values of those were available, and no generic method of tuning them has been developed at this point.

\subsection{Model Differential Equations}

Due to the size of the model, with 115 equations, which cannot all be presented in this document, the equations are mostly presented in the liquid phase, and give the general formulation used to derive the model dynamics, in both compartments, for all species and phases involved.

Moles in Reactor:

$$
\begin{aligned}
\frac{d N_{R u_{(s)}}}{d t} & =F_{R u_{(s)}}^{I n}-F_{R u_{(s)}}^{O u t}-r_{1} V_{r x_{(g)}} \\
\frac{d N_{i_{(l)}}}{d t} & =F_{i_{(l)}}^{I n}-F_{i_{(l)}}^{\text {Out }} \pm F_{i_{(l-g)}} \pm x_{i}^{r 1} \cdot r_{1} V_{r x_{(g)}} \pm x_{i}^{r 2} \cdot r_{2} V_{r x_{(l)}}
\end{aligned}
$$

Temperatures in Reactor:

$$
\begin{aligned}
\frac{d T_{r x_{(l)}}}{d t} & =\frac{1}{C p_{l}^{r x} \cdot N_{r x_{(l)}}^{\text {tot }}} \times\left(\sum _ { \text { Reaction, } i } \left(\left(-r_{1} V_{r x_{(g)}}+r_{2} V_{r x_{(l)}}\right) \times\left. C p^{i_{(l)}}\right|_{T_{r x_{(l)}}} \ldots\right.\right. \\
& \left.\left.\times\left(T_{r x_{(l)}}-T_{r e f}\right)\right)+H_{r x_{(l-l)}}+H_{r x_{(g-l)}}\right) \\
\frac{d T_{r x_{(g)}}}{d t} & =\frac{1}{C p_{g}^{r x} \cdot N_{r x_{(g)}}^{\text {tot }}} \times\left(\left.F_{C l_{2(g)}}^{I n} \cdot C p^{C l_{2(g)}}\right|_{T_{r x_{(g)}}^{I n}} \times\left(T_{r x_{(g)}}^{I n}-T_{r e f}\right) \ldots\right. \\
& \left.-\sum_{\substack{\text { Outlet } \\
\text { streams, } i}}\left(\left.F_{i_{(g)}^{\text {Out }}}^{\text {Out }} \cdot C p^{i_{(g)}}\right|_{T_{r x_{(g)}}} \times\left(T_{r x_{(g)}}-T_{r e f}\right)\right)+H_{r x_{(g-g)}}+H_{r x_{(l-g)}}\right)
\end{aligned}
$$

Moles in Jacket:

$$
\begin{aligned}
& \frac{d N_{\mathrm{H}_{2} \mathrm{O}_{(l)}}}{d t}=F_{C W}^{I n}-F_{C W}^{\text {Out }}-F_{\mathrm{H}_{2} \mathrm{O}_{(l-g)}} \\
& \frac{d N_{\mathrm{H}_{2} \mathrm{O}_{(g)}}}{d t}=F_{\text {Steam }}^{\text {In }}-F_{\text {Steam }}^{\text {Out }}+F_{\mathrm{H}_{2} \mathrm{O}_{(l-g)}}
\end{aligned}
$$


Temperatures in Jacket:

$$
\begin{aligned}
\frac{d T_{h x_{(l)}}}{d t} & =\frac{1}{C p_{l}^{h x} \cdot N_{h x_{(l)}}^{\text {tot }}} \times\left(\left(F_{C W}^{I n}+F_{\text {Steam }}^{\text {In }}\right) \cdot C p^{H_{2} O_{(l)}}\left(T_{h x_{(u t i l i t y)}}^{\text {In }}\right) \times \ldots\right. \\
& \left(T_{h x_{(u t i l i t y)}^{I n}}^{I n}-T_{r e f}\right)-\left(F_{C W}^{\text {Out }}+F_{\text {Steam }}^{\text {Out }}\right) \cdot C p_{l}^{h x} \times\left(T_{h x_{(l)}}-T_{r e f}\right) \ldots \\
& \left.+F_{H_{2} O_{(l-g)}} \cdot H_{v}^{H_{2} O}\left(T_{h x_{(l)}}\right)-H_{r x_{(l-l)}}\right)
\end{aligned}
$$

\subsection{Model Algebraic Equations}

A total of 97 algebraic equations were solved simultaneously with the 18 differential equations. The general formulation of the key algebraic equations are presented for the reactor compartment of the system only. The corresponding equations, in the jacket, were derived similarly.

\subsubsection{Reactor Side}

Total Moles:

$$
N_{r x(l)}^{t o t}=\sum_{\text {Species }, i} N_{i_{(l)}}
$$

Volumes:

Pressures:

$$
V_{r x_{(l)}}^{\text {tot }}=\sum_{\text {Species }, i} \frac{N_{i_{(l)}}}{\left.\rho_{i_{(l)}}\right|_{T_{r x}(l)}}
$$

$$
\begin{aligned}
P_{r x_{(g)}}^{t o t} & =\frac{N_{r x_{(g)}}^{t o t} \times R \times T_{r x_{(g)}}}{V_{r x_{(g)}}^{t o t}} \\
P_{r x_{(l)}}^{t o t} & =\rho_{r x_{(l)}} \times \mathrm{g} \times h_{r x_{(l)}}^{e q}+P_{r x_{(g)}}^{t o t}
\end{aligned}
$$

Rates of Reactions:

$$
\begin{aligned}
& r_{1}=k_{r 1} \times C_{C l_{2(g)}} \\
& r_{2}=k_{r 2} \times C_{R u C l} l_{3(l)} \times C_{\mathrm{NaClO}_{3(l)}}
\end{aligned}
$$

Heat Transfers from Liquid in Jacket to Liquid in Reactor:

$$
H_{r x_{(l-l)}}=\left(h_{r x_{(s)}}+h_{r x_{(l)}}\right) \times(2 \cdot \pi) \times\left(r_{r x}+w_{r x}\right) \times U_{l-l} \times\left(T_{h x_{(l)}}-T_{r x_{(l)}}\right)
$$

A total of four additional relations, similar to Equation 18, are calculated to account for the crossphase heat transfer between the two compartments. From liquid in jacket to solid and gas in reactor, then from gas in jacket to liquid and gas in reactor.

\section{Results and Discussion}

Simulating the model, the generated responses of temperature and pressure showed some good tracking of the batch data set they were compared to (see Figure 2). The model parameters were tuned by trial-and-error with a single batch run. A total of 28 different batches were simulated with those same parameters as the estimation could not be repeated for all batches.

\subsection{Explicit Model Simulations}

Figure 2a shows the model temperatures responses against the temperature data of a selected batch. In this simulation, steam and cooling water were supplied at the temperatures of $115^{\circ} \mathrm{C}$ and 27 ${ }^{\circ} C$, respectively. The reactor model was set at a steady state temperature of $30{ }^{\circ} \mathrm{C}$. The first subplot (top graph), shows the molar flow rates of the utilities pumped into the jacket. The second and third subplots (counting from top), demonstrate good tracking of batch data by the simulated temperatures responses. The bottom figure shows the dynamics of temperatures in the jacket of the reactor model, when subjected to the utility inputs. 

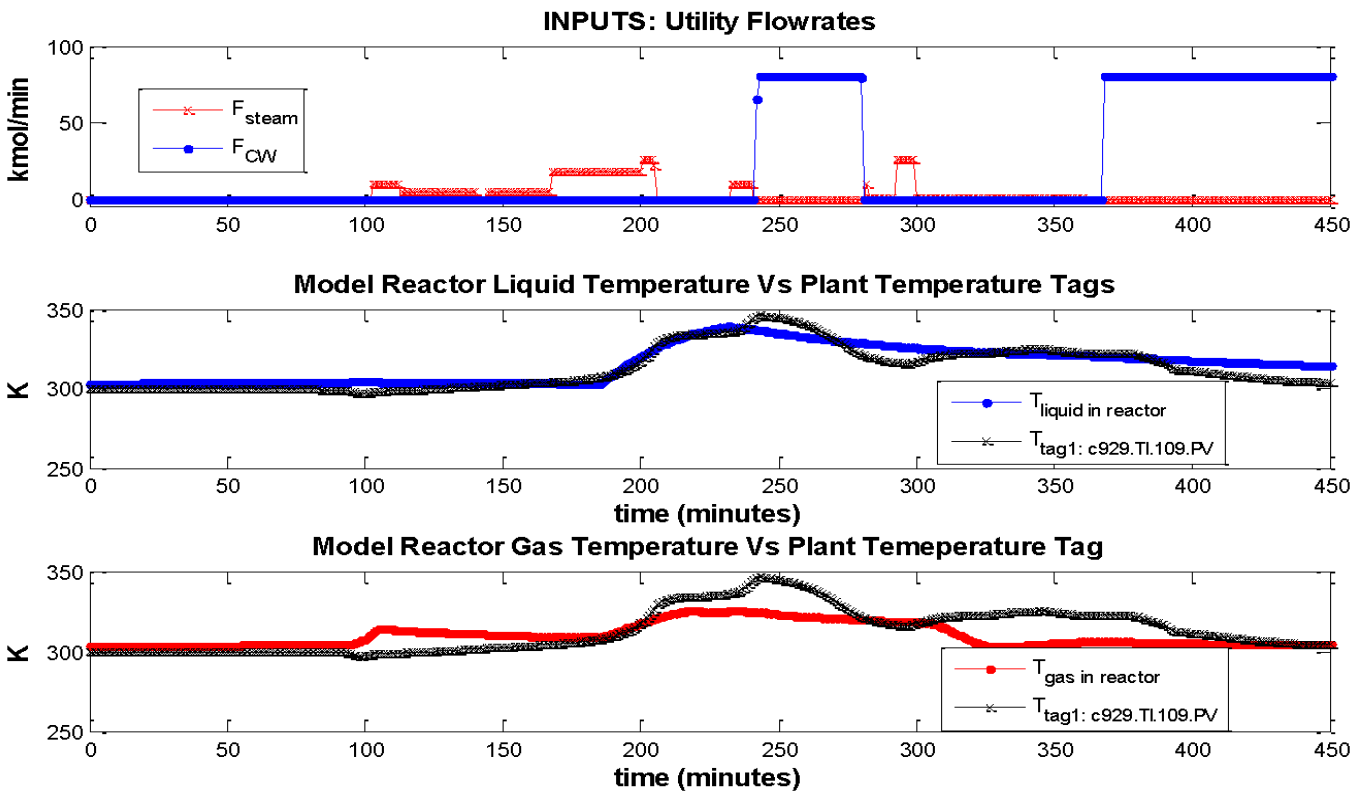

Model Responses for Jacket Temperatures (K)

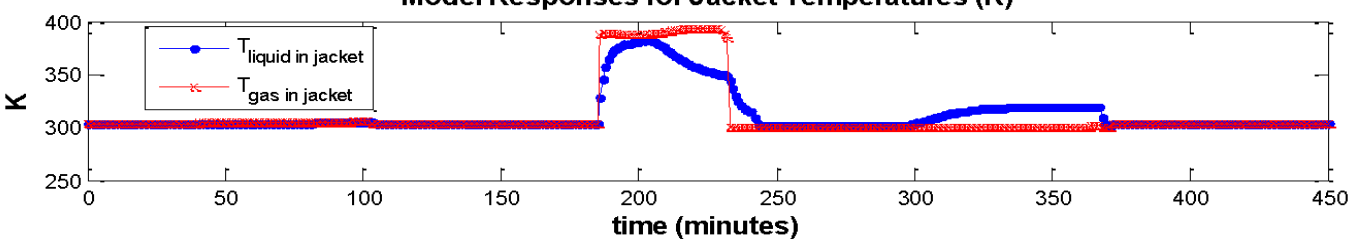

(a) Model Temperatures against Temperature Data
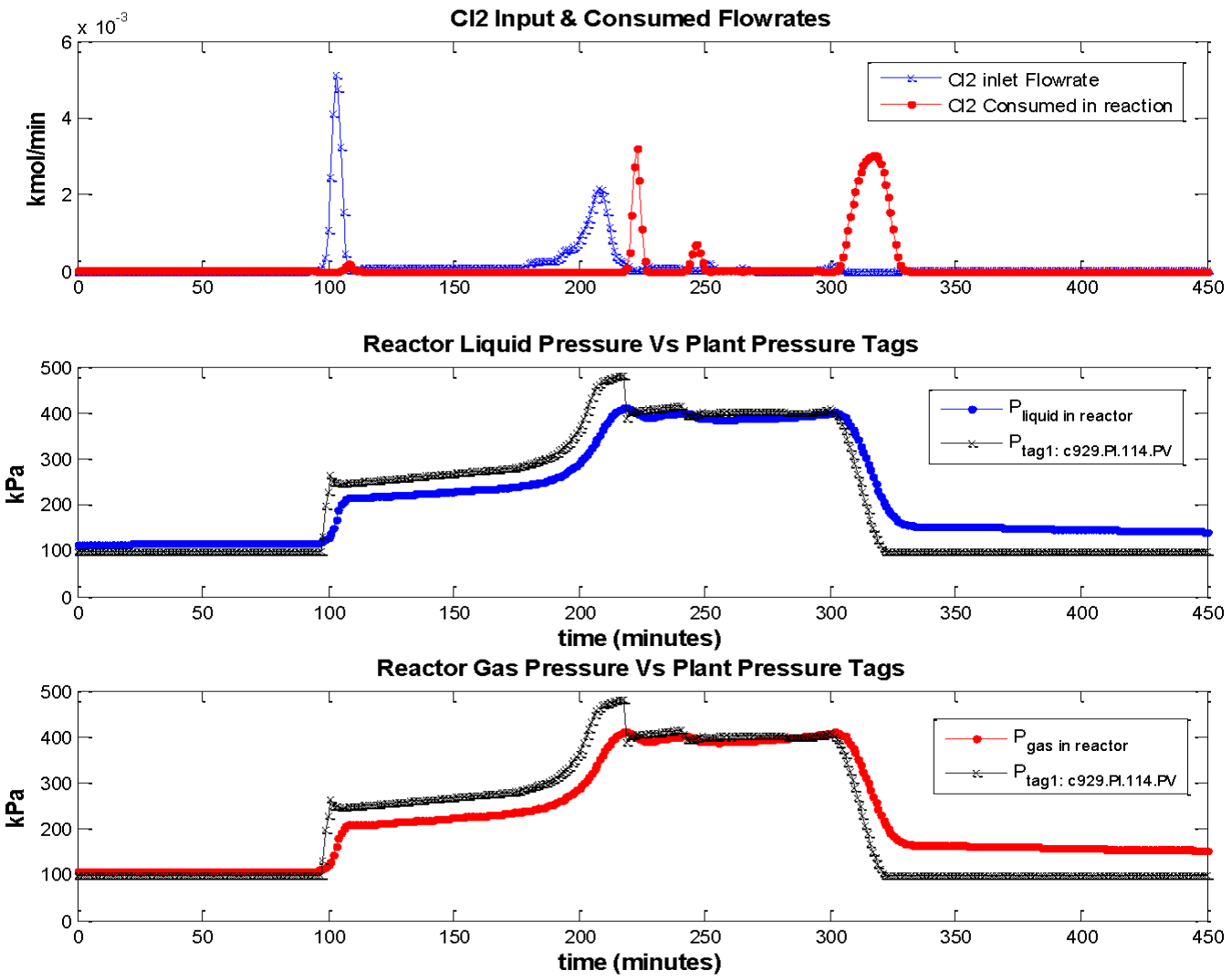

(b) Model Pressures against Pressure data

Figure 2: Temperature and Pressure responses 
Figure $2 \mathrm{~b}$ shows the model pressure responses against the pressure data of the same batch. During the reaction, the required pressure condition inside the reactor is achieved and maintained by pumping $\mathrm{Cl}_{2}$ gas into the reactor, at variable time intervals. The top graph of Figure $2 \mathrm{~b}$ shows the $\mathrm{Cl}_{2}$ (g) flow rate into to the reactor model and the amount of $\mathrm{Cl}_{2}(\mathrm{~g})$ consumed as the reaction proceeds. The second and third graphs, from the top, show the liquid and gas pressures of the reactor model, respectively. The model responses show a similar trend to that of the pressure data set $\left(\mathrm{P}_{\mathrm{tag} \text { 1: }}\right.$ 929.PI.114.PV $)$, although the pressure simulated responses do not track the pressure data very closely as some offset can be seen between the two.

\section{Conclusions}

We have developed a first-principle mathematical model of a ruthenium reactor. The aim of this work was to develop a model that could achieve good predictions of temperature and pressure dynamics of the real reactor. The parameters of heat and mass transfer coefficients, together with the reaction kinetic constants were estimated by trial-and-error. However, a more systematic method of parameterization is being developed, such that optimum parameters could be computed repeatedly as the model is run with various batches. The validation work, for better responses, is still in progress.

\section{Nomenclature}

$\mathrm{C}=$ Molar concentration

$\mathrm{C}_{\mathrm{p}}=$ Specific heat capacity at constant pressure

$\mathrm{CW}=$ Cooling Water

$\mathrm{H}=$ Enthalpy

$\mathrm{H}_{\mathrm{v}}=$ Heat of vaporization

$\mathrm{hx}=$ Jacket compartment

$\mathrm{h}_{\mathrm{rx}}=$ Height of reactor vessel

$\mathrm{i}=\mathrm{A}$ given specie

$\mathrm{k}_{\mathrm{i}}=$ Mass transfer coefficient of a given specie

$\mathrm{k}_{\mathrm{r} 1}=$ Kinetic constants of reaction 1

$\mathrm{N}_{\mathrm{Ru}_{(\mathrm{s})}}=$ Moles of ruthenium solid

$\mathrm{N}_{\left.\mathrm{i}_{()}\right)}=$Moles of specie in liquid phase

$\mathrm{r} 1=$ Reaction 1

$\mathrm{r}_{1}=$ Rate of reaction 1

$\mathrm{rx}=$ Reactor compartment

$\mathrm{r}_{\mathrm{rx}}=$ Radius of reactor vessel

$T_{\text {ref }}=$ Reference temperature

$\mathrm{U}=$ Heat transfer coefficient

$\mathrm{w}_{\mathrm{rx}}=$ Thickness of reactor wall

$x_{\mathrm{i}}^{\mathrm{r}}{ }^{1}=$ Stoichiometric constant of specie (i) in reaction 1

\section{References}

Hvala, N., Aller, F., Miteva, T., Kukanja, D., Oct. 2011. Modelling, simulation and control of an industrial, semi-batch, emulsion-polymerization reactor. Computers \& Chemical Engineering 35 (10), 2066-2080. URL http://linkinghub.elsevier.com/retrieve/pii/S0098135411001876

Hvala, N., Kukanja, D., Apr. 2013. Modelling and simulation of semi-batch polymerisation reactor for improved reactants dosing control. Simulation Modelling Practice and Theory 33, 102-114. URL http://linkinghub.elsevier.com/retrieve/pii/S1569190X12001360

Nyström, A., 2007. Modeling and simulation of a multi phase semi-batch reactor. SIMS 2007, 173-182. URL http://www.ep.liu.se/ecp/027/021/ecp072721.pdf

Pantelides, C., Renfro, J., Apr. 2013. The online use of first-principles models in process operations: Review, current status and future needs. Computers \& Chemical Engineering 51, 136-148. URL http://linkinghub.elsevier.com/retrieve/pii/S0098135412002360

Prokopová, Z., Prokop, R., 2009. Modelling And Simulation Of Chemical Industrial Reactors. ECMS (1). URLhttp://www.scs-europe.net/conf/ecms2009/ecms2009 CD/ecms2009 accepted papers/ind_0044_24232ee3.pdf 